\title{
The association between high particulate matter pollution and daily cause- specific hospital admissions: A time-series study in Yichang, China
}

Chengye Yao ${ }^{a, 1}$, Yu Wang ${ }^{b, 1}$, Christopher Williams ${ }^{c, 1}$, , Chengzhong Xud ${ }^{d}$, Christiana Kartsonakic,e, Yun Lin $^{\text {b, }}{ }^{*}$, Pei Zhang ${ }^{d, ~}{ }^{*}$, Peng Yin ${ }^{\dagger}$, Kin Bong Hubert Lam ${ }^{c}$

a Department of Neurology, Union Hospital, Tongji Medical College, Huazhong University of Science and Technology, Wuhan 430022, China

b Department of Anesthesiology, Institute of Anesthesia and Critical Care, Union Hospital, Tongji

Medical College, Huazhong University of Science and Technology, Wuhan 430022, China

c Nuffield Department of Population Health, University of Oxford, UK

d Yichang Center for Disease Control and Prevention, Yichang 443000, China

e Medical Research Council Population Health Research Unit, University of Oxford, UK

${ }^{\dagger}$ National Center for Chronic and Noncommunicable Disease Control and Prevention, Chinese Center for Disease Control and Prevention, Beijing 100050, China

${ }^{1}$ These individuals contributed equally to this article as co-first authors

*Correspondence to:

Dr. Yun Lin, Department of Anesthesiology, Institute of Anesthesia and Critical Care, Union Hospital, Tongji Medical College, Huazhong University of Science and Technology, No.1277, Jiefang Avenue, Wuhan 430022, China. Email: franklinyun@hust.edu.cn, telephone number: +8613986288403; and Dr. Pei Zhang, Yichang Center for Disease Control and Prevention, 3 Dalian Road, Yichang 443000 China. Email: zhangpeicdc@163.com

Acknowledgements: None. 


\section{ABSTRACT}

Particulate matter (PM) air pollution is one of the major causes of morbidity and mortality in China. In this study, we estimated the short-term effects of PM on cause-specific hospitalization in Yichang, China. Daily data for PM level, meteorological factors and hospital admissions (total hospitalization counts $=391,960)$ in Yichang between 2015 and 2017 were collected. We conducted a time-series study and applied a generalized additive model to evaluate the association between every $10-\mu \mathrm{g} / \mathrm{m}^{3}$ increment of PM and percent increase of hospitalization. We found positive and statistically significant associations between PM and hospital admissions for multiple outcomes, including allcause, total respiratory, total cardiovascular diseases and disease subcategories (hypertensive disease, coronary heart disease, stroke and the stroke subtype, chronic obstructive pulmonary disease and lower respiratory infection). Each $10-\mu \mathrm{g} / \mathrm{m}^{3}$ increase in $\mathrm{PM}_{2.5}$ at Lag01 (a moving average of Lag0 to Lag1), was significantly associated with an increase of $1.31 \%(95 \% \mathrm{Cl}: 0.79 \%$, $1.83 \%), 1.12 \%(95 \% \mathrm{Cl}: 0.40 \%, 1.84 \%)$ and $1.14 \%(95 \% \mathrm{Cl}: 0.53 \%, 1.75 \%)$ in hospitalizations for allcause, CVD and respiratory respectively. The association for $\mathrm{PM}_{10}$ with all-cause, CVD and respiratory admissions was similar but weaker than $\mathrm{PM}_{2.5}$. The effect on admissions persisted for up to seven days, and peaked at Lag01. The associations between PM and all-cause hospitalizations were stronger among older individuals and in cold seasons. It is therefore important to continue implementation of emission abatement and other effective measures in Yichang and other cities in China.

Keywords: air pollution; hospital admissions; $\mathrm{PM}_{2.5} ; \mathrm{PM}_{10}$; cardiovascular disease; respiratory disease; time-series study 


\section{INTRODUCTION}

Exposure to high levels of particulate matter (PM) with aerodynamic diameter $\leq 10 \mu m\left(\mathrm{PM}_{10}\right)$ and $\leq 2.5 \mu \mathrm{m}$ ( $\mathrm{PM}_{2.5}$ ), a pollutant arising from a variety of natural and man-made sources, has been consistently shown to be associated with excess mortality (Cohen et al. 2017, Dominici et al. 2006, McGowan et al. 2002). More recently, the Global Burden of Disease Study (Cohen et al. 2017) in 2015 estimated that $\mathrm{PM}_{2.5}$ was the fifth-ranking risk factor for mortality and responsible for 4.2 million deaths worldwide. Similar health risks have been identified for $\mathrm{PM}_{10}$ (Zhou et al. 2014).

By contrast, evidence for an association between PM levels and morbidity, such as hospitalizations for specific diseases, has been limited and non-conclusive (Atkinson et al. 2014, Schikowski et al. 2014, Stafoggia et al. 2013). The evidence is strongest for cardiovascular disease (CVD) admissions as reported by a recent meta-analysis (Atkinson et al. 2014) of 100 time-series studies, conducted mainly in high-income countries, which found a statistically-significant positive association. A study in eight cities in Southern Europe (Stafoggia et al. 2013) showed significant associations between all PM fractions and respiratory hospitalizations. Another recent systematic review (Schikowski et al. 2014) concluded that there was suggestive evidence of an association with chronic obstructive pulmonary disease (COPD). However, none of the studies included in this systematic review were from Asia.

The majority of the evidence on the associations between PM pollution and hospitalizations has been from North America and Europe, but the exposure levels in these regions are substantially lower than elsewhere, such as in major cities in China (Gurung et al. 2017). A meta-analysis (Newell et al. 2017) on the effects of PM has demonstrated variations in cardiorespiratory morbidity and mortality between regions for exposure to both $\mathrm{PM}_{2.5}$ and $\mathrm{PM}_{10}$. Therefore, it is essential that the effect of $\mathrm{PM}$ pollution is also investigated in specific localities at high risk and not extrapolated from Western data.

In China, some studies on the association between PM pollution and hospitalizations have been conducted in different cities (Appendix A: Table. A1-2). Some recent nationwide studies have used data from Urban Employee Basic Medical Insurance database, which focused on urban and retired employees, to explore the association between PM pollution and total hospitalizations or hospitalization due to single disease (Tian et al. 2018a, Tian et al. 2018b). While the study devoted to the association between PM pollution and the hospitalizations for various diseases is still scarce. Furthermore, most previous studies have considered PM singly, without considering the potential confounding or effect modification by other air pollutants, such as $\mathrm{CO}$ (carbon monoxide), $\mathrm{NO}_{2}$ (nitrogen dioxide), $\mathrm{SO}_{2}$ (sulfur dioxide) and $\mathrm{O}_{3}$ (ozone). Yichang, a city in the Hubei Province in central east China, is one of the very few cities in China where data from most hospitals and multiple air pollutants are collected systematically and integrated into a single database. Hence, Yichang is well-placed for researching the effects of PM pollution on hospital admissions in China. The main aim of this study is to determine if there is an association between episodes of high levels of $\mathrm{PM}_{2.5}$ or $\mathrm{PM}_{10}$ and all-cause, respiratory and CVD hospitalizations, in Yichang, China.

\section{Materials and Methods}




\subsection{Data collection}

Daily inpatient data for two of the largest tier three hospitals ( $\geq 500$ beds) in the city of Yichang (accounting for $57.9 \%$ of all admissions from tier three hospitals) were obtained from the Big Data Center of Yichang Center for Disease Control and Prevention, covering the period between January 1, 2015 and December 31, 2017. This study focuses on inpatient data rather than outpatient data because in China it is common for patients to visit different hospitals on the same day to get different opinions, and so multiple outpatient visits might account for the same patient. Anonymized hospital admissions records were classified by the International Classification of Diseases (ICD), $10^{\text {th }}$ revision, for CVD (ICD10: I00-199) and respiratory (ICD10: J00-J99). Selected disease subcategories included hypertensive disease (ICD: I10-15), coronary heart disease (CHD) (I20-24), stroke (I60-69), ischemic stroke (Istroke) (ICD: 160-62), hemorrhagic stroke (Hstroke) (ICD: I63), COPD (J41-44) and lower respiratory infection (Lowres) (ICD: J12-18, J20-J22). Daily hospital admissions were further categorized by gender and age group ( $<65 ; \geq 65$ years of age). As only aggregated non-identifiable data were used, ethics approval and consent from individuals were not required.

Air pollutant data were collected at one-hour intervals and included measurements of $\mathrm{PM}_{2.5}$ $\left(\mu \mathrm{g} / \mathrm{m}^{3}\right), \mathrm{PM}_{10}\left(\mu \mathrm{g} / \mathrm{m}^{3}\right), \mathrm{SO}_{2}\left(\mu \mathrm{g} / \mathrm{m}^{3}\right), \mathrm{NO}_{2}\left(\mu \mathrm{g} / \mathrm{m}^{3}\right), \mathrm{CO}\left(\mathrm{mg} / \mathrm{m}^{3}\right)$ and $\mathrm{O}_{3}$ (8-hour average) $\left(\mu \mathrm{g} / \mathrm{m}^{3}\right)$. The data for each pollutant was an average of the daily readings from each of the air quality monitoring stations by the Yichang Municipal Bureau of Environmental Protection. Data on air pollutants were missing for 2 days, accounting for only $0.18 \%$ of the total number of days in the study period; they were excluded from the analysis. We also collected the AQI (Air Quality Index) which is an index to present the six pollutants with a unified evaluation criteria. The calculation formula of the AQI can be found in the methodological details of the appendix. Data on daily mean temperature $\left({ }^{\circ} \mathrm{C}\right)$ and daily relative humidity (\%) were retrieved from the Big Data Center.

\subsection{Statistical analysis}

Air pollutants, meteorological variables, and hospital admissions were described as means \pm standard deviations (SD) with minimum, $25^{\text {th }}, 50^{\text {th }}, 75^{\text {th }}$ centiles and maximum values. Pearson correlation coefficients were calculated to assess the degree of correlation between air pollutants and meteorological variables.

Generalized additive models (GAM) were used in our study and Quasi-Poisson regression was used because hospital admissions tended to display an over-dispersed Poisson distribution. A cubic spline function of calendar time with seven degrees of freedom (DF) per year was used to account for unmeasured long-term and seasonal trends (Chen et al. 2017, Chen et al. 2018). Cubic spline functions were also used for current-day temperature (6 DF) and humidity (3 DF), to allow for adjustment of potential meteorological factors (Cai et al. 2014). Season, defined as cold (October March) and warm (April - September) and day of the week were also included in the basic model. Different lag structures were examined and the lag periods included 0-7 days and a two-day moving average lag of 0 and 1 days (Lag01). Lag01 was used for the main analyses because episodes of high levels of PM are likely to influence health outcomes for more than 24 hours and, thus, single-day lag models might underestimate the cumulative effect (Chen et al. 2010). Disease subcategories were 
also assessed using the model at Lag0 to Lag3 and Lag01. Finally, exposure-response curves were created using the same models at Lag01 additionally using a spline function to model the exposure variable. Additional analyses were conducted to explore the potential modifications by age, gender and season subgroups using the same model fitted in each subgroup at Lag01. Wald tests were used to determine if the effects were significantly different between the subgroups.

Additional multi-pollutant models were fitted to test the robustness of the associations of $\mathrm{PM}_{2.5}$ and $\mathrm{PM}_{10}$ with hospitalizations. The association of other pollutants $\left(\mathrm{CO}, \mathrm{SO}_{2}, \mathrm{NO}_{2}\right.$ and $\left.\mathrm{O}_{3}\right)$ and hospitalization were also assessed using the model at Lag0 to Lag3 and Lag01. To check whether model parameters were appropriate for this study, analyses were repeated using 4-9 DF which had been used in similar time-series analyses (Tao et al. 2014, Tian et al. 2017, Xu et al. 2017).

The parameter estimates were presented as the percentage changes of daily admissions for a $10 \mu \mathrm{g} / \mathrm{m}^{3}$ increase of $\mathrm{PM}_{2.5}$ or $\mathrm{PM}_{10}$, with their corresponding $95 \%$ confidence intervals (Cls). P-values are two sided and $\mathrm{P}<0.05$ is considered statistically significant. All models were fitted using $R$ software (version 3.5.0, R Foundation for Statistical Computing, Vienna, Austria) with the mgcv package (Chen et al. 2018).

\section{Results}

\subsection{Summary statistics}

Table 1 shows the summary statistics for the study. During the study period (2015-2017) there were a total of 391,960 inpatient admissions in the two hospitals included, of which $50 \%$ were in males, $33 \%$ were in individuals aged 65 years or more, and 50\% took place during the cold season. The number of CVD admissions ( $n=45,510,11.6 \%$ of total) was greater than that of respiratory admissions ( $n=37,051,9.5 \%$ of total). The most common cause of CVD admission was CHD, and Lowres showed the greatest number of admissions among respiratory diseases with a mean of 11 per day.

Pearson correlation coefficients suggest there is a high correlation between $\mathrm{PM}_{2.5}$ and $\mathrm{PM}_{10}$, and moderately high correlations for $\mathrm{PM}_{2.5}, \mathrm{PM}_{10}, \mathrm{CO}$ and $\mathrm{NO}_{2}$ (Table 2). In general, air pollutants displayed a weak negative correlation with temperature and humidity. 
Table 1 Summary statistics for daily measurements of hospital admissions, air pollutants and meteorological variables, in Yichang, from January 1, 2015 to December 31, 2017

\begin{tabular}{|c|c|c|c|c|c|c|c|c|c|}
\hline & Variables & Number & Mean & SD & Min & P25 & P50 & P75 & Max \\
\hline \multicolumn{2}{|c|}{ All-cause Daily Admissions } & 391,960 & 358 & 123 & 38 & 266 & 365 & 434 & 840 \\
\hline \multirow[t]{2}{*}{ Gender } & Male & 195,492 & 178 & 63 & 16 & 131 & 179 & 220 & 465 \\
\hline & Female & 196,468 & 179 & 63 & 22 & 133 & 181 & 218 & 474 \\
\hline \multirow[t]{2}{*}{ Age } & $<65$ & 294,628 & 269 & 91 & 35 & 203 & 273 & 325 & 634 \\
\hline & $\geq 65$ & 97,332 & 268 & 96 & 25 & 63 & 87 & 112 & 606 \\
\hline \multirow[t]{2}{*}{ Season } & Cold & 197,582 & 361 & 135 & 38 & 264 & 369 & 444 & 840 \\
\hline & Warm & 194,378 & 354 & 109 & 105 & 272 & 359 & 429 & 796 \\
\hline \multicolumn{2}{|c|}{ CVD Admissions (ICD: 100-99) } & 45,510 & 42 & 17 & 2 & 30 & 40 & 52 & 115 \\
\hline \multicolumn{2}{|c|}{ Hypertensive disease (ICD: I10-15) } & 5,337 & 5 & 3 & 0 & 2 & 4 & 7 & 23 \\
\hline \multicolumn{2}{|c|}{ CHD (ICD: I20-24) } & 16,786 & 15 & 8 & 0 & 10 & 14 & 19 & 51 \\
\hline \multicolumn{2}{|c|}{ Stroke (ICD: I60-69) } & 11,068 & 10 & 5 & 0 & 6 & 9 & 13 & 33 \\
\hline \multicolumn{2}{|c|}{ Istroke (ICD: I60-62) } & 7,369 & 7 & 4 & 0 & 4 & 6 & 9 & 28 \\
\hline \multicolumn{2}{|c|}{ Hstroke (ICD: I63) } & 2,170 & 2 & 1 & 0 & 1 & 2 & 3 & 12 \\
\hline \multicolumn{2}{|c|}{ Respiratory Admissions (ICD: J00-99) } & 37,051 & 34 & 12 & 3 & 25 & 33 & 41 & 133 \\
\hline \multicolumn{2}{|c|}{ COPD (ICD: J41-44) } & 8,168 & 8 & 4 & 0 & 4 & 7 & 10 & 28 \\
\hline \multicolumn{2}{|c|}{ Lowres (ICD: J12-18, J20-J22) } & 11,747 & 11 & 6 & 0 & 7 & 10 & 14 & 64 \\
\hline \multicolumn{10}{|c|}{ Pollutant Concentrations and Meteorological Variables (24-h Average) } \\
\hline \multicolumn{3}{|c|}{$\mathrm{PM}_{2.5}\left(\mu \mathrm{g} / \mathrm{m}^{3}\right)$} & 63.0 & 45.8 & 4.5 & 31.2 & 51.5 & 80.7 & 317.8 \\
\hline \multicolumn{3}{|c|}{$\mathrm{PM}_{10}\left(\mu \mathrm{g} / \mathrm{m}^{3}\right)$} & 99.4 & 57.0 & 10.1 & 60.4 & 86.4 & 125.5 & 409.0 \\
\hline \multicolumn{3}{|c|}{$\mathrm{CO}\left(\mathrm{mg} / \mathrm{m}^{3}\right)$} & 1.1 & 0.3 & 0.3 & 0.9 & 1.0 & 1.2 & 2.6 \\
\hline \multicolumn{3}{|c|}{$\mathrm{NO}_{2}\left(\mu \mathrm{g} / \mathrm{m}^{3}\right)$} & 34.6 & 10.1 & 12.8 & 27.0 & 33.3 & 40.4 & 81.2 \\
\hline \multicolumn{3}{|c|}{$\mathrm{O}_{3}\left(8\right.$ Hour Average) $\left(\mu \mathrm{g} / \mathrm{m}^{3}\right)$} & 45.5 & 24.1 & 10.4 & 26.6 & 41.8 & 58.5 & 165.2 \\
\hline \multicolumn{3}{|c|}{$\mathrm{SO}_{2}\left(\mu \mathrm{g} / \mathrm{m}^{3}\right)$} & 14.9 & 9.7 & 3.4 & 9.3 & 12.0 & 16.3 & 81.8 \\
\hline \multicolumn{3}{|l|}{ AQI } & 92.6 & 53.6 & 16.2 & 57.7 & 76.8 & 111.4 & 367.5 \\
\hline \multicolumn{3}{|c|}{ Mean Temperature $\left({ }^{\circ} \mathrm{C}\right)$} & 16.8 & 8.1 & -1.4 & 9.5 & 17.4 & 23.9 & 32.6 \\
\hline \multicolumn{3}{|c|}{ Mean Humidity (\%) } & 77.2 & 14.1 & 30.5 & 66.9 & 77.6 & 88.8 & 99.0 \\
\hline
\end{tabular}


Note: $A Q I$ is an index to present the six pollutants with a unified evaluation criteria

Abbreviations: CVD: cardiovascular disease; CHD: coronary heart disease; Istroke: ischemic stroke; Hstroke: hemorrhagic stroke; COPD: chronic obstructive pulmonary disease; Lowres: lower respiratory infection; AQI: Air Quality Index; SD: standard deviation; Min: minimum; P25: the 25th percentile; P50: the 50th percentile; P75: the 75th percentile; Max: maximum

Table 2 Pearson correlation coefficients between daily air pollutant concentrations and weather conditions in Yichang

\begin{tabular}{|c|c|c|c|c|c|c|c|}
\hline & $\mathbf{P M}_{10}$ & CO & $\mathrm{NO}_{2}$ & $\mathrm{SO}_{2}$ & $\begin{array}{c}\mathrm{O}_{3} \text { (8-Hour } \\
\text { Average) }\end{array}$ & Temperature & $\begin{array}{l}\text { Relative } \\
\text { Humidity }\end{array}$ \\
\hline $\mathrm{PM}_{2.5}$ & 0.95 & 0.76 & 0.67 & 0.66 & -0.34 & -0.55 & -0.17 \\
\hline $\mathrm{PM}_{10}$ & & 0.67 & 0.68 & 0.66 & -0.25 & -0.47 & -0.29 \\
\hline CO & & & 0.58 & 0.42 & -0.43 & -0.52 & 0.06 \\
\hline $\mathrm{NO}_{2}$ & & & & 0.39 & -0.28 & -0.43 & -0.30 \\
\hline $\mathrm{SO}_{2}$ & & & & & -0.28 & -0.47 & -0.23 \\
\hline \multicolumn{3}{|c|}{$\mathrm{O}_{3}$ (8-Hour Average) } & & & & 0.59 & -0.27 \\
\hline Temp & & & & & & & 0.05 \\
\hline
\end{tabular}

\subsection{Association of PM with hospitalizations}

The associations of $\mathrm{PM}_{2.5}$ with admissions varied by lag structure and admission type. Statistically significant associations were observed for $\mathrm{PM}_{2.5}$ at Lag01 for all-cause, CVD and respiratory admissions with increases in hospitalizations of $1.31 \%(95 \% \mathrm{Cl}$ : $0.79 \%, 1.83 \%), 1.12 \%(95 \% \mathrm{Cl}$ : $0.40 \%, 1.84 \%)$ and $1.14 \%(95 \% \mathrm{Cl}: 0.53 \%, 1.75 \%)$ respectively per $10 \mu \mathrm{g} / \mathrm{m}^{3}$ increase of $\mathrm{PM}_{2.5}$ (Fig 1a). The association weakened for all admission types as the lag structure increased from 0 to 5 . The association between $\mathrm{PM}_{10}$ with admissions for all-cause, CVD and respiratory disease was similar, but weaker, to that of $\mathrm{PM}_{2.5}$. For a $10 \mu \mathrm{g} / \mathrm{m}^{3}$ increase of $\mathrm{PM} 10$, all-cause, CVD, respiratory admissions increased by $0.99 \%(95 \% \mathrm{Cl}$ : $0.59 \%, 1.39 \%), 0.97 \%(95 \% \mathrm{Cl}: 0.42 \%, 1.52 \%)$ and $0.66 \%(95 \% \mathrm{Cl}$ : $0.19 \%, 1.13 \%$ ), respectively (Fig 1b). The peak associated percentage increase in all-cause admissions, CVD admissions and respiratory admissions occurred at Lag01 for both $\mathrm{PM}_{2.5}$ and $\mathrm{PM}_{10}$. For all-cause admissions, the positive effect of both $\mathrm{PM}_{2.5}$ and $\mathrm{PM}_{10}$ persisted for up to seven days (Lag6). For analysis of disease subcategories, the associations of $\mathrm{PM}_{2.5}$ (Fig 2a) and $\mathrm{PM}_{10}$ (Fig 2b) with hospital admissions for most disease (hyper diseases, CHD, stroke, Istroke, COPD and Lowres) except Hstroke were statistically significant and positive at Lag01. 
Fig 1 Estimated percentage change (and $95 \%$ Cls) of hospital admissions by disease categories associated with a $10 \mu \mathrm{g} / \mathrm{m}^{3}$ increase in $\mathrm{PM}_{2.5}(\mathrm{a})$ and $\mathrm{PM} 2.5$ (b) with different lag periods

Note: The Y-axis is the percent increases; the points indicate central estimates; Bars, 95\% confidence intervals. Abbreviations: CVD - Cardiovascular Disease.

a

Adimision Type Lag (Days)

All-cause

CVD

VD

Respiratory

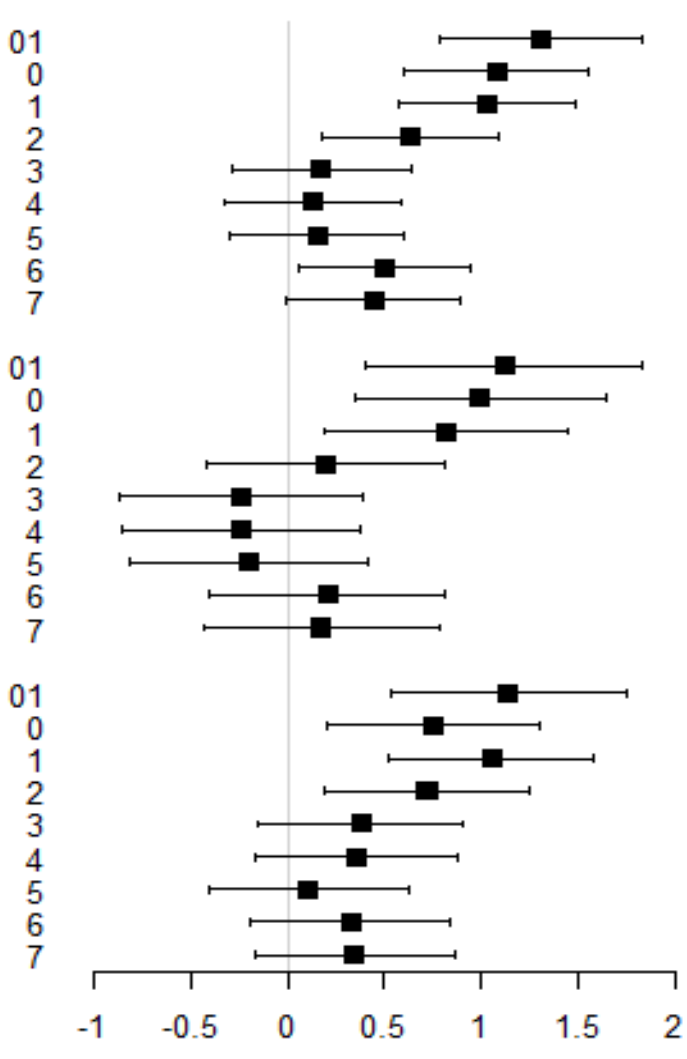

b

Adimision Type Lag (Days)

All-cause

CVD

Respiratory

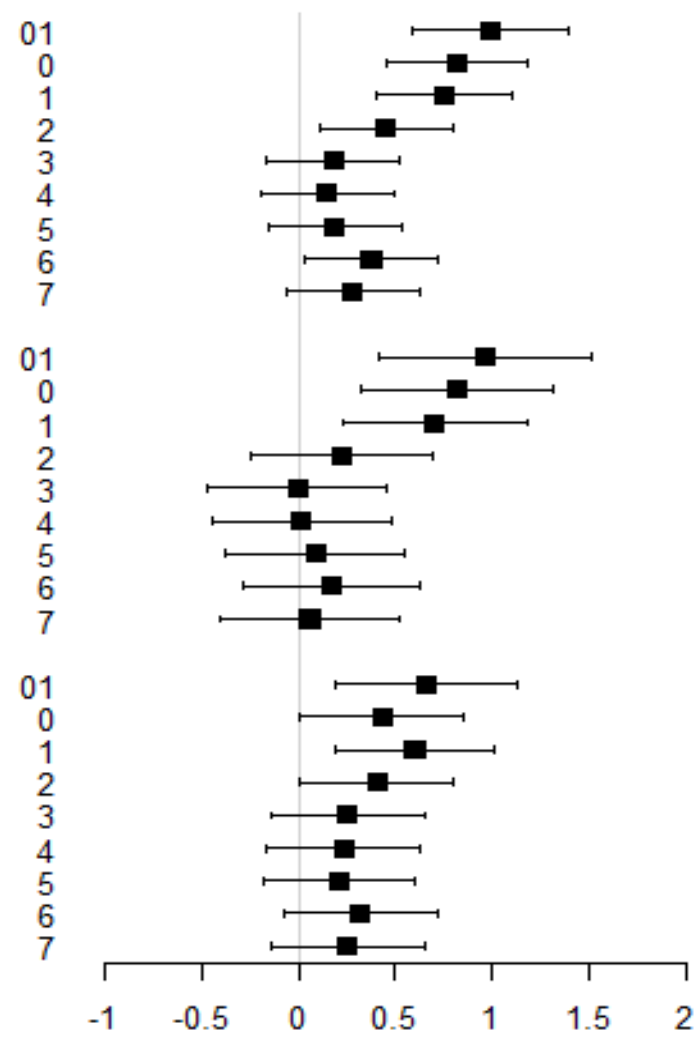


Fig 2 Estimated percentage change (and $95 \% \mathrm{Cls}$ ) of hospital admissions by disease subcategories associated with a $10 \mu \mathrm{g} / \mathrm{m}^{3}$ increase in PM 2.5 (a) and $\mathrm{PM}_{2.5}$ (b) with different lag periods

Note: The $\mathrm{Y}$-axis is the percent increases; the points indicate central estimates; Bars, 95\% confidence intervals

Abbreviations: CVD - Cardiovascular Disease; CHD - Coronary Heart Disease; Istroke - Ischemic stroke; Hstroke - Hemorrhagic stroke; COPD - Chronic obstructive pulmonary disease; Lowres - Lower respiratory infection

Adimision Type

Subcategory Lag (Days)

CVD

Hypertensive Disease

CHD

Stroke

Hstroke

$$
\begin{array}{r}
01 \\
0 \\
1 \\
2 \\
3
\end{array}
$$

Istroke

Respiratory Disease

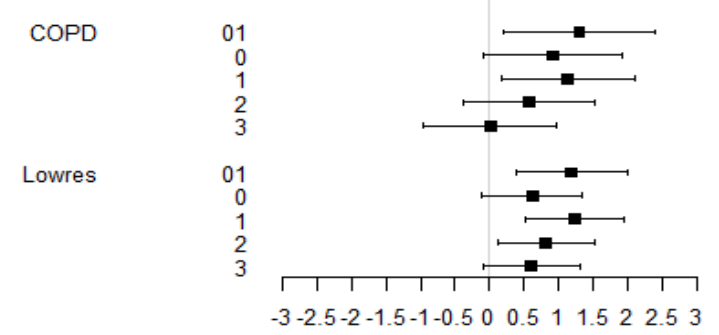

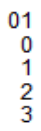

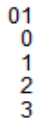

b

Adimision Type

CVD
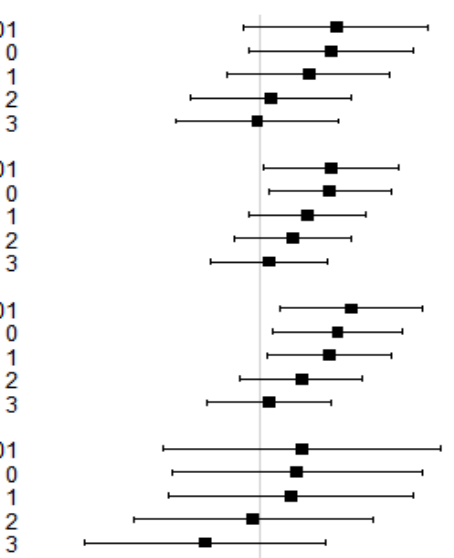

01
0
1
2

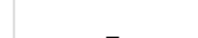

Istroke

Respiratory Disease

Hypertensive Disease

CHD

Stroke

Hstroke

COPD

Lowres
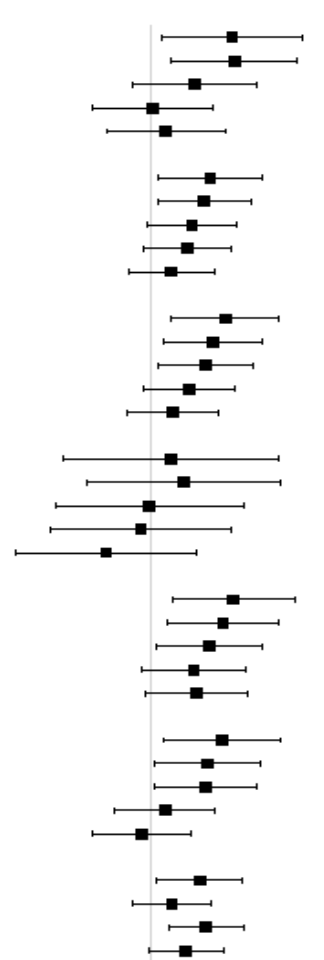

1, 1 1 1 1 1

$-3-2.5-2-1.5-1-0.500 .5111 .522 .5$ 
The exposure-response curves shown in Fig 3 strongly suggests that the relative risk of admissions increases for all admission types as PM increases. The increase in risk is approximately linear above $50 \mu \mathrm{g} / \mathrm{m}^{3}$ of $\mathrm{PM}_{2.5}$ for all admission types, except for respiratory conditions, For $\mathrm{PM}_{10}$, there is a nearly linear relationship between all-cause and CVD admissions above approximately $75 \mu \mathrm{g} / \mathrm{m}^{3}$. The associations of $\mathrm{PM}_{2.5}$ and $\mathrm{PM}_{10}$ with all-cause and $\mathrm{CVD}$ are J-shaped, with the lowest observed admissions at approximately $50 \mu \mathrm{g} / \mathrm{m}^{3}$ of $\mathrm{PM}_{2.5}$ and $75 \mu \mathrm{g} / \mathrm{m}^{3}$ of $\mathrm{PM}_{10}$.

Fig 3 Exposure response curves of $\mathrm{PM}_{2.5}$ and $\mathrm{PM}_{10}$ measured in per $\mu \mathrm{g} / \mathrm{m}^{3}$ against All-Cause Hospital Admissions, CVD Admissions and Respiratory Admissions

Note: The $\mathrm{X}$-axis is the concentrations of $\mathrm{PM}_{2.5}$ and $\mathrm{PM}_{10}$ on the Lag01 days. The $\mathrm{Y}$-axis is the log relative risk. The solid line represents the predicted log relative risk, and the dotted lines represent the 95\% confidence intervals

Abbreviations: CVD, Cardiovascular Disease
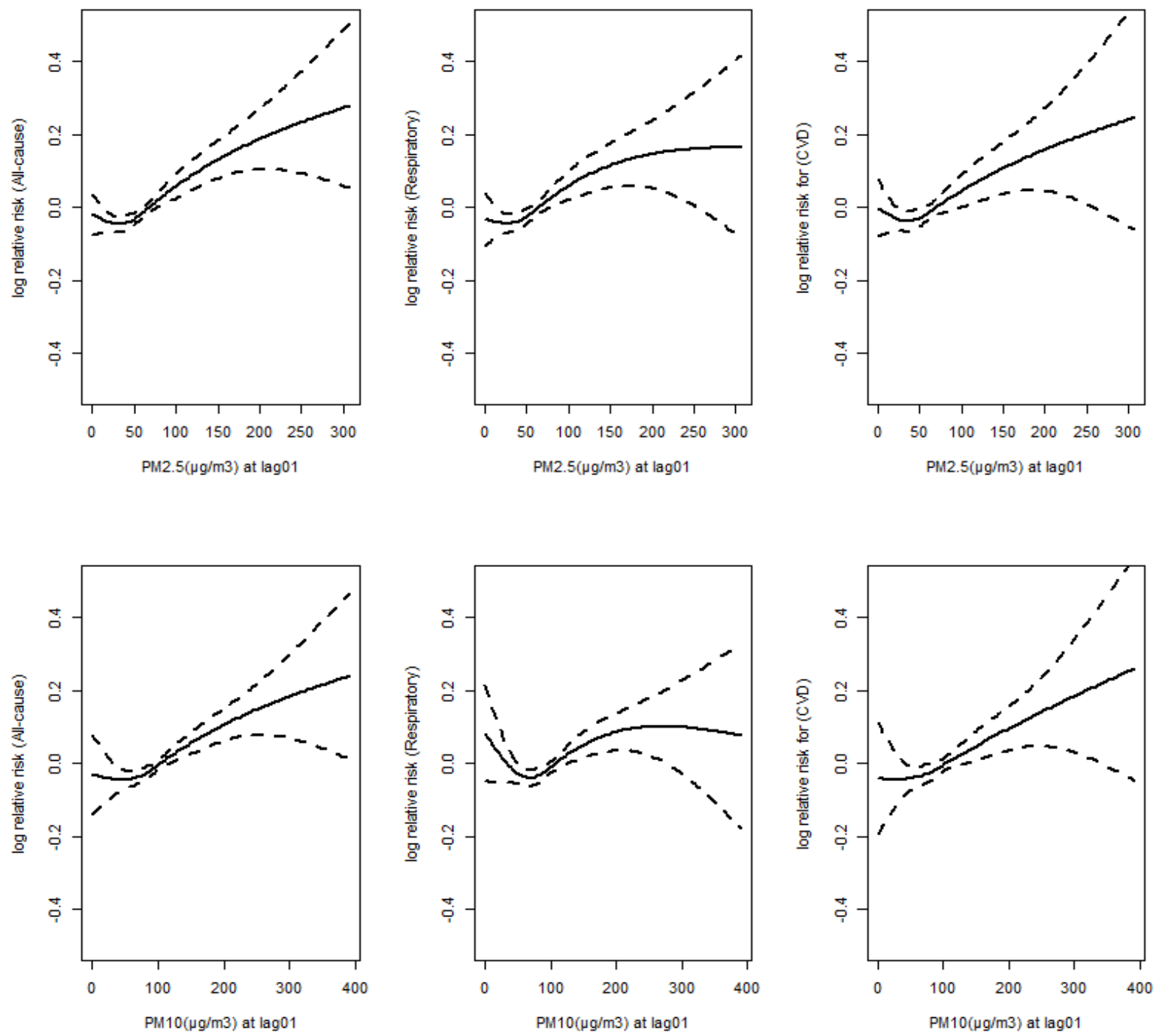


\subsection{Stratified analyses}

Stratified analyses by age for $\mathrm{PM}_{2.5}$ showed a statistically significant difference between age groups ( $<65$ years of age and $\geq 65$ years of age) for all-cause admissions and respiratory admissions $(P<0.05)$. For $\mathrm{PM}_{10}$ there was only a statistically significant difference between the two age groups for respiratory admissions $(P<0.05)$. The investigation into differences in association by sex showed no statistically significant difference in associations of $\mathrm{PM}_{2.5}$ or $\mathrm{PM}_{10}$ with any of the hospital admission types. The associations were stronger in the cold season in all-cause admissions and differences in association by season were observed for all-cause admissions for both $\mathrm{PM}_{2.5}$ and $\mathrm{PM}_{10}$. Estimated increase in hospital admissions in relation to a $10-\mu \mathrm{g} / \mathrm{m}^{3}$ increase in PM at Lag01 for age-, gender-, and season-specific groups were shown in Table 3. 
Table 3 Estimated increase in hospital admissions in relation to a $10 \mu \mathrm{g} / \mathrm{m}^{3}$ increase in PM at Lag01 for age-, gender-, and season-specific groups

\begin{tabular}{|c|c|c|c|}
\hline & \multirow[t]{3}{*}{ Admissions } & \multicolumn{2}{|c|}{ Percentage $(\%)$ increase in hospitalizations $(95 \% \mathrm{Cl})$} \\
\hline & & \multicolumn{2}{|c|}{ Age Group (Years) } \\
\hline & & $<65$ & $\geq 65$ \\
\hline \multirow{3}{*}{$\mathrm{PM}_{2.5}$} & All-cause & $1.26(0.74,1.78)^{*}$ & $1.47(0.81,2.13)^{*}$ \\
\hline & Total CVD & $0.80(-0.04,1.63)$ & $1.49(0.63,2.35)$ \\
\hline & Total Respiratory & $0.96(0.32,1.60)^{*}$ & $1.69(0.61,2.77)^{\star}$ \\
\hline \multirow[t]{5}{*}{$\mathbf{P M}_{10}$} & All-cause & $0.95(0.55,1.34)$ & $1.13(0.63,1.64)$ \\
\hline & Total CVD & $0.75(0.11,1.39)$ & $1.22(0.56,1.87)$ \\
\hline & Total Respiratory & $0.47(-0.02,0.96)^{*}$ & $1.25(0.42,2.08)^{*}$ \\
\hline & & \multicolumn{2}{|c|}{ Gender } \\
\hline & & Male & Female \\
\hline \multirow[t]{3}{*}{$\mathrm{PM}_{2.5}$} & All-cause & $1.35(0.78,1.91)$ & $1.27(0.72,1.82)$ \\
\hline & Total CVD & $0.97(0.15,1.79)$ & $1.32(0.45,2.19)$ \\
\hline & Total Respiratory & $1.07(0.37,1.78)$ & $1.24(0.41,2.07)$ \\
\hline \multirow[t]{5}{*}{$\mathrm{PM}_{10}$} & All-cause & $0.97(0.53,1.40)$ & $1.02(0.59,1.44)$ \\
\hline & Total CVD & $0.79(0.16,1.42)$ & $1.20(0.54,1.87)$ \\
\hline & Total Respiratory & $0.54(0.00,1.09)$ & $0.83(0.19,1.47)$ \\
\hline & & \multicolumn{2}{|c|}{ Season } \\
\hline & & Cold & Warm \\
\hline \multirow[t]{3}{*}{$\mathrm{PM}_{2.5}$} & All-cause & $1.20(0.53,1.87)^{\star}$ & $-0.16(-1.17,0.84)^{*}$ \\
\hline & Total CVD & $0.98(0.11,1.86)$ & $0.98(-0.58,2.55)$ \\
\hline & Total Respiratory & $1.09(0.33,1.85)$ & $-0.37(-1.86,1.12)$ \\
\hline \multirow[t]{3}{*}{$\mathrm{PM}_{10}$} & All-cause & $0.82(0.27,1.36)^{\star}$ & $0.01(-0.64,0.66)^{*}$ \\
\hline & Total CVD & $0.77(0.07,1.48)$ & $0.30(-0.70,1.31)$ \\
\hline & Total Respiratory & $0.53(-0.07,1.14)$ & $-0.53(-1.49,0.43)$ \\
\hline
\end{tabular}

Note: *Statistically significant for between-group difference $(P<0.05)$.

Abbreviations: CVD, Cardiovascular Disease. 


\subsection{Sensitivity Analyses}

The risk estimates were statistically significant from multi-pollutant models, as shown in Table 4, suggesting the associations are robust. The associated percentage increase of hospital admissions per $10 \mu \mathrm{g} / \mathrm{m}^{3}$ increase of $\mathrm{PM}$ following adjustment for $\mathrm{NO}_{2}$ and $\mathrm{SO}_{2}$ attenuated and became statistically insignificant for CVD or respiratory disease, but the direction of the association was consistent. The results on gaseous pollutants and hospital admissions in China can be found in Appendix A: Table. A3. We observed statistically significant and positive risk estimates of $\mathrm{CO}, \mathrm{NO}_{2}$ and $\mathrm{SO}_{2}$ on the hospitalizations for all-cause, $\mathrm{CVD}$ and respiratory disease (except the estimate of $\mathrm{CO}$ on CVD hospitalizations) at Lag01. Further analyses with different DF for time (Appendix A: Table. A4) showed that $95 \% \mathrm{Cls}$ of the risk estimates were smallest and furthest away from zero at $7 \mathrm{DF}$, suggesting model parameters were appropriate at 7 DF in this study.

Table 4 Hospital admissions percentage increase $(95 \% \mathrm{Cls})$ for per $10 \mu \mathrm{g} / \mathrm{m}^{3}$ increase in PM in multipollutant models with a 01 moving average lag from January 1st, 2015 to December 31st, 2017

\begin{tabular}{lccc}
\hline & \multicolumn{2}{c}{ Percentage (\%) increase in hospitalizations (95\% Cl) } \\
\cline { 2 - 4 } Pollutants & All-cause & Total CVD & Total Respiratory \\
\hline $\mathbf{P M}_{2.5}$ & $0.99(0.59,1.39)$ & $0.97(0.42,1.52)$ & $0.66(0.19,1.13)$ \\
$\mathbf{P M}_{2.5}+\mathbf{S O}_{2}$ & $0.71(0.26,1.15)$ & $0.76(0.15,1.36)$ & $0.40(-0.12,0.92)$ \\
$\mathbf{P M}_{2.5}+\mathbf{N O}_{2}$ & $0.69(0.25,1.13)$ & $0.71(0.10,1.31)$ & $0.26(-0.26,0.78)$ \\
$\mathbf{P M}_{2.5}+\mathbf{C O}$ & $0.97(0.53,1.40)$ & $1.02(0.43,1.62)$ & $0.52(0.00,1.04)$ \\
$\mathbf{P M}_{2.5}+\mathbf{O}_{3}$ (8 Hour Average) & $1.05(0.64,1.45)$ & $1.01(0.45,1.56)$ & $0.65(0.18,1.12)$ \\
\hline $\mathbf{P M}_{10}$ & $1.31(0.79,1.83)$ & $1.12(0.40,1.84)$ & $1.14(0.53,1.75)$ \\
$\mathbf{P M}_{10}+\mathbf{S O}_{2}$ & $0.87(0.25,1.50)$ & $0.76(-0.10,1.62)$ & $0.84(0.12,1.56)$ \\
$\mathbf{P M}_{10}+\mathbf{N O}_{2}$ & $0.79(0.13,1.44)$ & $0.60(-0.29,1.50)$ & $0.51(-0.24,1.26)$ \\
$\mathbf{P M}_{10}+\mathbf{C O}$ & $1.65(0.95,2.35)$ & $1.60(0.64,2.56)$ & $1.17(0.36,1.98)$ \\
$\mathbf{P M}_{10}+\mathbf{O}_{3}$ (8 Hour Average) & $1.49(0.94,2.03)$ & $1.24(0.50,1.99)$ & $1.16(0.53,1.78)$ \\
\hline
\end{tabular}

Abbreviations: CVD, Cardiovascular Disease. 


\section{Discussion}

This study of 391,960 hospital admissions in Yichang, China, shows that PM is associated with an increase in all-cause, respiratory disease and CVD hospital admissions. There is an association with all-cause admissions on the same day and persist for up to seven days. The association is stronger for $\mathrm{PM}_{2.5}$ than $\mathrm{PM}_{10}$. Episodes of high levels of $\mathrm{PM}$ in the cold season are still frequent in Yichang and, thus, these findings may have implications for the prevention and management of hospital admissions.

Some studies from both China and other countries have shown increases in hospital admissions when PM concentrations rise (Bell et al. 2013, Huang et al. 2016, Tao et al. 2014). In general, previous literature suggests the relationships between $\mathrm{PM}_{10}$ and hospital admissions are weaker than the relationships observed for the same disease outcome with PM2.5 (Bell et al. 2013, Huang et al. 2016, Tao et al. 2014). This trend is supported by the findings of our study as the strength of the relationships observed for $\mathrm{PM}_{10}$ was weaker than those observed for $\mathrm{PM}_{2.5}$ and displays similar temporal patterns.

In this study, the admissions for CVD at Lag01 increased when concentrations of PM rise and this positive association is supported by previous literature. Zanobetti et al. conducted a time-series study on 26 communities in the United States and estimated that CVD admissions increased by $1.89 \%$ (95\% Cl: $1.34 \%, 2.45 \%$ ) per $10 \mu \mathrm{g} / \mathrm{m}^{3}$ of $\mathrm{PM}_{2.5}$ at Lag01 (Zanobetti et al. 2009). Our study supports that CVD admissions are positively associated with $\mathrm{PM}_{2.5}$ but suggests the strength of the effect is weaker in Yichang (with 1.12\% CVD admissions increase for per $10 \mu \mathrm{g} / \mathrm{m}^{3}$ increase of $\mathrm{PM}_{2.5}$ ). This might be due to underlying differences in the two populations or the composition of the PM in each region. Moreover, this difference could suggest that the increase in effect of $\mathrm{PM}_{2.5}$ is greater at lower concentrations and weakens as the concentrations increase because the mean concentration of $\mathrm{PM}_{2.5}$ was lower in the study by Zanobetti et al (Zanobetti et al. 2009). A downward trend in exposureresponse has been previously suggested for China but not for Europe where the exposures are generally smaller (Lu et al. 2015). In our study, the association between $\mathrm{PM}_{2.5}$ and admissions for hypertensive disease was not statistically significant. A meta-analysis of a review study on $\mathrm{PM}_{2.5}$ in China found that the highest effect estimate out of all the included morbidity studies was on hypertension (Pui et al. 2014), while other studies in the review study did not show a significant association of $\mathrm{PM}_{2.5}$ and hypertensive disease and this is potentially due to their smaller sample size. Recently, nationwide studies using data from medical insurance records of urban current and retired employees have been performed on the on the association between PM pollution and hospitalizations in China. They test the association of $\mathrm{PM}_{2.5}$ and Istroke hospital admissions (Tian et al. 2018a) and observed $0.34 \%(95 \% \mathrm{Cl}, 0.20 \%-0.48 \%)$ increases in hospital admissions of Istroke for per $10 \mu \mathrm{g} / \mathrm{m}^{3}$ increase in $\mathrm{PM}_{2.5}$. Our results showed admissions for Istroke had the strongest association with PM among all CVD subcategories. While the association between PM and admissions for Hstroke was not statistically significant, which was consistent with a previous multi-city studies in China (Liu et al. 2017). 
Respiratory disease admissions were associated with both $\mathrm{PM}_{2.5}$ and $\mathrm{PM}_{10}$ in this study and the association was largest at Lag01. The temporal pattern of PM and respiratory disease admissions was inconsistent. Previous literature in Western countries has identified relative risks were generally larger at longer lags for total respiratory admissions, and it has been suggested that the exact temporal pattern is to some extent dependent on the constituents of the PM (Kim et al. 2012). Therefore, it is important to know the source of pollutants in each area to predict the delay associated with an increase in respiratory admissions. Our study also estimated a percent increase for COPD and Lowres hospitalizations for both $\mathrm{PM}_{2.5}$ and $\mathrm{PM}_{10}$ increase. The prevalence of COPD is increasing worldwide and the increase of PM pollution was related to the increased risks for COPD mortality and COPD hospital admission, ranging between 2 and 3\%. (Heinrich \&Schikowski 2018). Lowres are the most frequent causes of hospital admission in children worldwide. An eight-year study on children showed strong associations between hospital admissions for Lowres and daily levels of PM pollution (Nhung et al. 2018).

In this study, the exposure-response curves for PM concentrations against respiratory hospitalizations were much flatter than for all-cause and CVD admissions. This finding supports the previous literature, which suggests the effects of $P M$ concentrations are weaker for respiratory diseases than CVD (Ren et al. 2017, Stafoggia et al. 2013). The shape of the exposure-response plot plays a role in public health assessment, and it is essential to have localised exposure-response relationships for proper prevention. With adjustment for other pollutants like $\mathrm{CO}$ and $\mathrm{O}_{3}$, the association remained stable, while attenuated for CVD or respiratory disease with adjustment for $\mathrm{NO}_{2}$ and $\mathrm{SO}_{2}$, but the direction of the association was consistent. We performed the separate analysis of the association between changes in the levels of other substances and hospitalization (Appendix: Table A3). The estimated percent increase of hospitalizations were most strong for the increase of $\mathrm{NO}_{2}$ and $\mathrm{SO}_{2}$, so the effect of PM may be complex as a component of the whole air pollutants.

Our study suggests that older age groups are more likely to be admitted to hospital with a respiratory condition following an increase in PM concentration. Previous studies in China support this finding, such as Tao and colleagues' five-year study in Lanzhou on $\mathrm{PM}_{10}$ (Tao et al. 2014). The literature on the season differences in association between PM and respiratory disease is mixed. Some studies have found differences in association similar to the findings observed here (Stafoggia et al. 2008) in Italy, whereas others have found the opposite effect in Western China (Wang et al. 2013). It is possible these results are contradictive because of the differences between the geographies of the study locations and distinctive cultural norms in each site around habits such as smoking, alcohol consumption and diet. In this study there was no evidence of any differences in associations with CVD admissions by age group or season. Previous findings are contradictory in this respect for differences by age with some evidence indicating that those in older age groups are at a greater risk of death or being admitted to hospital for CVD (Le Tertre et al. 2002, Yin et al. 2017) and others finding no evidence of a differences in association (Su et al. 2016). Similar discrepancies exist among results for differences by season in the associations with CVD (Huang et al. 2016, Serinelli et al. 2010). Thus, it is unclear whether different relationships exist for CVD by season. 
Several plausible biological explanations have been previously suggested to explain the associations between PM and CVD (Fiordelisi et al. 2017, Kennedy et al. 1998, Xia et al. 2004). The direct effects are based upon two mechanisms: firstly, PM could potentially induce excessive reactive oxygen species, which are known to cause CVD; and secondly it has been hypothesised that PM stimulates peroxide production which in turn affects calcium regulation resulting in cardiomyocyte hypertrophy (Fiordelisi et al. 2017). An indirect mechanism hypothesised is that the inhalation of pollutants triggers pulmonary oxidative stress (Kennedy et al. 1998). This limits vascular function, stimulates atherosclerosis and mobilises haemostatic pathways (Suwa et al. 2002). The lung is exposed to air pollutants more frequently than many other organs and, thus, is more prone to oxidantmediated damage. Similar to CVD, if a person is at high risk of developing or already suffering from a respiratory condition, an increase in PM might exacerbate underlying symptoms through these mechanisms and result in a hospitalization.

As previously mentioned, few studies have been conducted on the health effects of PM pollution in the central regions of China. Therefore, this study provided new insight into the health problems associated with PM pollution. The study included almost $60 \%$ of tier three hospital inpatient data for Yichang, covered a much larger proportion of hospital admissions than studies conducted in other cities in China. Hospitalization data were collected routinely at the point of admission, as such recall bias is avoided. This study has included data over three years, resulting in having a large number of hospitalizations and therefore providing good statistical power to examine the disease subcategories. The statistical analysis was further strengthened by the completeness of the dataset with only $0.18 \%$ of data missing from the analysis. Finally, by using a time-series approach, as opposed to a casecrossover approach, this study was more effective for controlling for meteorological variables (Fung et al. 2003).

Our study also has some limitations. By choosing a time-series design over a case-crossover design, a number of confounding variables could not be included in the model, such as smoking status, family history and occupational exposure. However, these are unlikely to have substantial effect on the estimates because these individual-level confounding factors are unlikely to be timevarying. As with many previous studies, air pollution recordings were simply an average measure across fixed-site monitoring stations and used as a proxy for air pollution exposure in Yichang. This will likely underestimate the effects of PM (Goldman et al. 2011). We were only able to include $60 \%$ of all inpatient data from tier three hospitals in Yichang, therefore the possibility of selection bias could not be ruled out. Some recent nationwide studies have conducted on urban and retired employees, to explore the association between PM pollution and total hospitalizations or hospitalization due to single disease (Tian et al. 2018a, Tian et al. 2018b). Our study, however, targeted the total population and used hospital data to test the association between air pollution and hospital admissions for multiple diseases based on the standard ICD codes for diagnosis. Finally, as with all time-series studies examining the associations of PM with health outcomes, this study design is ecological in nature and thus the ability for causal inference is limited.

\section{Conclusion}


The findings of this study imply that hospitals in Yichang might experience higher admissions of CVD and respiratory disease immediately and during episodes of high levels of PM. There is a significant health risk associated with increased PM and so it is important measures to reduce PM emissions to be continued in Yichang and elsewhere in China. Moreover, this study has shown some findings that are different to those in elsewhere in China and so it is important to conduct further research in other cities in China rather than extrapolating findings from other provinces and regions.

Funding: This research did not receive any specific grant from funding agencies in the public, commercial, or not-for-profit sectors.

\section{Compliance with Ethical Standards}

\section{Conflict of Interest}

The authors declare they have no actual or potential competing financial interests.

\section{Ethics Approval}

This study does not involve experimental animals or individual information of human subjects. 


\section{References:}

Atkinson RW, Kang S, Anderson HR, Mills IC, Walton HA (2014) Epidemiological time series studies of PM2.5 and daily mortality and hospital admissions: a systematic review and meta-analysis. Thorax 69: 660-5. http://doi.org/10.1136/thoraxjnl-2013-204492

Bell ML, Zanobetti A, Dominici F (2013) Evidence on vulnerability and susceptibility to health risks associated with short-term exposure to particulate matter: a systematic review and meta-analysis. Am J Epidemiol 178: 865-76. http://doi.org/10.1093/aje/kwt090

Cai J, Zhao A, Zhao J, Chen R, Wang W, Ha S, Xu X, Kan H (2014) Acute effects of air pollution on asthma hospitalization in Shanghai, China. Environ Pollut 191: 139-44. http://doi.org/10.1016/j.envpol.2014.04.028

Chen C, Liu C, Chen R, Wang W, Li W, Kan H, Fu C (2018) Ambient air pollution and daily hospital admissions for mental disorders in Shanghai, China. Sci Total Environ 613-614: 324-330. http://doi.org/10.1016/j.scitotenv.2017.09.098

Chen R, Chu C, Tan J, Cao J, Song W, Xu X, Jiang C, Ma W, Yang C, Chen B, Gui Y, Kan H (2010) Ambient air pollution and hospital admission in Shanghai, China. J Hazard Mater 181: 234-40. http://doi.org/10.1016/j.jhazmat.2010.05.002

Chen R, Yin P, Meng X, Liu C, Wang L, Xu X, Ross JA, Tse LA, Zhao Z, Kan H, Zhou M (2017) Fine Particulate Air Pollution and Daily Mortality. A Nationwide Analysis in 272 Chinese Cities. Am J Respir Crit Care Med 196: 73-81. http://doi.org/10.1164/rccm.201609-1862OC

Cohen AJ et al. (2017) Estimates and 25-year trends of the global burden of disease attributable to ambient air pollution: an analysis of data from the Global Burden of Diseases Study 2015. Lancet 389 : 1907-1918. http://doi.org/10.1016/S0140-6736(17)30505-6

Dominici F, Peng RD, Bell ML, Pham L, McDermott A, Zeger SL, Samet JM (2006) Fine particulate air pollution and hospital admission for cardiovascular and respiratory diseases. JAMA 295: 1127-34. http://doi.org/10.1001/jama.295.10.1127

Fiordelisi A, Piscitelli P, Trimarco B, Coscioni E, laccarino G, Sorriento D (2017) The mechanisms of air pollution and particulate matter in cardiovascular diseases. Heart Fail Rev 22: 337-347. http://doi.org/10.1007/s10741-017-9606-7

Fung KY, Krewski D, Chen Y, Burnett R, Cakmak S (2003) Comparison of time series and casecrossover analyses of air pollution and hospital admission data. Int J Epidemiol 32: 1064-70.

Goldman GT, Mulholland JA, Russell AG, Strickland MJ, Klein M, Waller LA, Tolbert PE (2011) Impact of exposure measurement error in air pollution epidemiology: effect of error type in time-series studies. Environ Health 10: 61. http://doi.org/10.1186/1476-069X-10-61

Gurung A, Son JY, Bell ML (2017) Particulate Matter and Risk of Hospital Admission in the Kathmandu Valley, Nepal: A Case-Crossover Study. Am J Epidemiol 186: 573-580. http://doi.org/10.1093/aje/kwx135

Heinrich J, Schikowski T (2018) COPD Patients as Vulnerable Subpopulation for Exposure to Ambient Air Pollution. Curr Environ Health Rep 5: 70-76. http://doi.org/10.1007/s40572-018-0178-z Huang F, Luo Y, Guo Y, Tao L, Xu Q, Wang C, Wang A, Li X, Guo J, Yan A, Guo X (2016) Particulate Matter and Hospital Admissions for Stroke in Beijing, China: Modification Effects by Ambient 
Temperature. J Am Heart Assoc. http://doi.org/10.1161/JAHA.116.003437

Kennedy T, Ghio AJ, Reed W, Samet J, Zagorski J, Quay J, Carter J, Dailey L, Hoidal JR, Devlin RB (1998) Copper-dependent inflammation and nuclear factor-kappaB activation by particulate air pollution. Am J Respir Cell Mol Biol 19: 366-78. http://doi.org/10.1165/ajrcmb.19.3.3042

Kim SY, Peel JL, Hannigan MP, Dutton SJ, Sheppard L, Clark ML, Vedal S (2012) The temporal lag structure of short-term associations of fine particulate matter chemical constituents and cardiovascular and respiratory hospitalizations. Environ Health Perspect 120: 1094-9. http://doi.org/10.1289/ehp.1104721

Le Tertre A, Medina S, Samoli E, Forsberg B, Michelozzi P, Boumghar A, Vonk JM, Bellini A, Atkinson R, Ayres JG, Sunyer J, Schwartz J, Katsouyanni K (2002) Short-term effects of particulate air pollution on cardiovascular diseases in eight European cities. J Epidemiol Community Health 56 : 773-9.

Liu H, Tian Y, Xu Y, Huang Z, Huang C, Hu Y, Zhang J (2017) Association between ambient air pollution and hospitalization for ischemic and hemorrhagic stroke in China: A multicity case-crossover study. Environ Pollut 230: 234-241. http://doi.org/10.1016/j.envpol.2017.06.057

Lu F, Xu D, Cheng Y, Dong S, Guo C, Jiang X, Zheng X (2015) Systematic review and meta-analysis of the adverse health effects of ambient PM2.5 and PM10 pollution in the Chinese population. Environ Res 136: 196-204. http://doi.org/10.1016/j.envres.2014.06.029

McGowan JA, Hider RN, Chacko E, Town GI (2002) Particulate air pollution and hospital admissions in Christchurch, New Zealand. Aust N Z J Public Health 26: 23-9.

Newell K, Kartsonaki C, Lam K, Kurmi OP (2017) Cardiorespiratory health effects of particulate ambient air pollution exposure in low-income and middle-income countries: a systematic review and meta-analysis. Lancet Planet Health 1: e368-e380. http://doi.org/10.1016/S2542-5196(17)30166-3

Nhung N, Schindler C, Dien TM, Probst-Hensch N, Perez L, Kunzli N (2018) Acute effects of ambient air pollution on lower respiratory infections in Hanoi children: An eight-year time series study. Environ Int 110: 139-148. http://doi.org/10.1016/j.envint.2017.10.024

Pui DYH, Chen SC, Zuo Z (2014) PM 2.5 in China: Measurements, sources, visibility and health effects, and mitigation. Particuology 13: 1-26.

Ren M, Fang X, Li M, Sun S, Pei L, Xu Q, Ye X, Cao Y (2017) Concentration-Response Relationship between PM2.5 and Daily Respiratory Deaths in China: A Systematic Review and Metaregression Analysis of Time-Series Studies. Biomed Res Int 2017: 5806185. http://doi.org/10.1155/2017/ 5806185

Schikowski T, Mills IC, Anderson HR, Cohen A, Hansell A, Kauffmann F, Kramer U, Marcon A, Perez L, Sunyer J, Probst-Hensch N, Kunzli N (2014) Ambient air pollution: a cause of COPD? Eur Respir J 43: 250-63. http://doi.org/10.1183/09031936.00100112

Serinelli M, Vigotti MA, Stafoggia M, Berti G, Bisanti L, Mallone S, Pacelli B, Tessari R, Forastiere F (2010) Particulate matter and out-of-hospital coronary deaths in eight Italian cities. Occup Environ Med 67: 301-6. http://doi.org/10.1136/oem.2009.046359

Stafoggia M, Schwartz J, Forastiere F, Perucci CA (2008) Does temperature modify the association between air pollution and mortality? A multicity case-crossover analysis in Italy. Am J Epidemiol 167: 
1476-85. http://doi.org/10.1093/aje/kwn074

Stafoggia M, Samoli E, Alessandrini E, Cadum E, Ostro B, Berti G, Faustini A, Jacquemin B, Linares C, Pascal M, Randi G, Ranzi A, Stivanello E, Forastiere F (2013) Short-term associations between fine and coarse particulate matter and hospitalizations in Southern Europe: results from the MEDPARTICLES project. Environ Health Perspect 121: 1026-33. http://doi.org/10.1289/ehp.1206151

Su C, Breitner S, Schneider A, Liu L, Franck U, Peters A, Pan X (2016) Short-term effects of fine particulate air pollution on cardiovascular hospital emergency room visits: a time-series study in Beijing, China. Int Arch Occup Environ Health 89: 641-57. http://doi.org/10.1007/s00420-015-1102-6 Suwa T, Hogg JC, Quinlan KB, Ohgami A, Vincent R, van Eeden SF (2002) Particulate air pollution induces progression of atherosclerosis. J Am Coll Cardiol 39: 935-42.

Tao Y, Mi S, Zhou S, Wang S, Xie X (2014) Air pollution and hospital admissions for respiratory diseases in Lanzhou, China. Environ Pollut 185, 196-201. http://doi.org/10.1016/j.envpol.2013.10.035 Tian Y, Xiang X, Wu Y, Cao Y, Song J, Sun K, Liu H, Hu Y (2017) Fine Particulate Air Pollution and First Hospital Admissions for Ischemic Stroke in Beijing, China. Sci Rep 7: 3897. http://doi.org/10.1038/s41598-017-04312-5

Tian Y, Liu H, Zhao Z, Xiang X, Li M, Juan J, Song J, Cao Y, Wang X, Chen L, Wei C, Hu Y, Gao P (2018a) Association between ambient air pollution and daily hospital admissions for ischemic stroke: A nationwide time-series analysis. PloS Med 15: e1002668. http: //doi.org/10.1371/ journal. pmed. 1002668

Tian Y, Liu H, Liang T, Xiang X, Li M, Juan J, Song J, Cao Y, Wang X, Chen L, Wei C, Gao P, Hu Y (2018b) Ambient air pollution and daily hospital admissions: A nationwide study in 218 Chinese cities. Environ Pollut 242: 1042-1049. http://doi.org/10.1016/j.envpol.2018.07.116

Wang MZ, Zheng S, Wang SG, Tao Y, Shang KZ (2013) The weather temperature and air pollution interaction and its effect on hospital admissions due to respiratory system diseases in western China. Biomed Environ SCI 26: 403-7. http://doi.org/10.3967/0895-3988.2013.05.011

Xia T, Korge P, Weiss JN, Li N, Venkatesen MI, Sioutas C, Nel A (2004) Quinones and aromatic chemical compounds in particulate matter induce mitochondrial dysfunction: implications for ultrafine particle toxicity. Environ Health Perspect 112: 1347-58. http://doi.org/10.1289/ehp.7167

Xu A, Mu Z, Jiang B, Wang W, Yu H, Zhang L, Li J (2017) Acute Effects of Particulate Air Pollution on Ischemic Heart Disease Hospitalizations in Shanghai, China. Int J Environ Res Public Health. http://doi.org/10.3390/ijerph14020168

Yin P, He G, Fan M, Chiu KY, Fan M, Liu C, Xue A, Liu T, Pan Y, Mu Q, Zhou M (2017) Particulate air pollution and mortality in 38 of China's largest cities: time series analysis. BMJ 356: j667. http://doi.org/10.1136/bmj.j667

Zanobetti A, Franklin M, Koutrakis P, Schwartz J (2009) Fine particulate air pollution and its components in association with cause-specific emergency admissions. Environ Health 8: 58. http://doi.org/10.1186/1476-069X-8-58

Zhou M, Liu Y, Wang L, Kuang X, Xu X, Kan H (2014) Particulate air pollution and mortality in a cohort of Chinese men. Environ Pollut 186: 1-6. http://doi.org/10.1016/j.envpol.2013.11.010 